\title{
Sociedade civil e democracia: o Grupo de Visegrado em perspetiva comparada
}

Civil Society and Democracy: The Visegrad Group in a Comparative Perspective Société civile et démocratie: le Groupe de Visegrád en perspective comparative

Mariana Carmo Duarte

\section{OpenEdition}

\section{Journals}

Edição electrónica

URL: http://journals.openedition.org/rccs/9488

DOI: $10.4000 /$ rccs.9488

ISSN: 2182-7435

\section{Editora}

Centro de Estudos Sociais da Universidade de Coimbra

Edição impressa

Data de publição: 1 dezembro 2019

Paginação: 33-52

ISSN: 0254-1106

Refêrencia eletrónica

Mariana Carmo Duarte, « Sociedade civil e democracia: o Grupo de Visegrado em perspetiva comparada », Revista Crítica de Ciências Sociais [Online], 120 | 2019, posto online no dia 12 dezembro 2019, consultado o 14 dezembro 2019. URL : http://journals.openedition.org/rccs/9488 ; DOI : $10.4000 /$ rccs. 9488 


\title{
MARIANA CARMO DUARTE
}

\section{Sociedade civil e democracia: o Grupo de Visegrado em perspetiva comparada*}

\begin{abstract}
Este artigo tem como objetivo inferir sobre a influência da sociedade civil na qualidade da democracia nos países do Grupo de Visegrado (Eslováquia, Hungria, Polónia e República Checa). Para tal, foi mapeada a evolução da sociedade civil nestes Estados, assim como mobilizados os principais debates teóricos em torno do tema. Recorrendo a dados de inquéritos internacionais ao longo de três períodos distintos, conclui-se que a adesão dos cidadãos a organizações voluntárias da sociedade civil é fraca nos quatro países. No entanto, no que diz respeito às diferenças, a República Checa apresenta os melhores níveis de participação em organizações voluntárias, em oposição à Polónia que apresenta os piores. Quando analisada a relação entre sociedade civil, associativismo e democracia, é possível concluir que embora estes países possam estar a enfrentar uma deriva autoritária, esta não deve ser imputada aos fracos níveis de associativismo.
\end{abstract}

Palavras-chave: associativismo; autoritarismo; democracia; Europa Central; Europa de Leste; sociedade civil.

\section{Introdução}

Em 1989, a queda do muro de Berlim desencadeou o início dos processos de transição democrática nos países da Europa Central e de Leste, nos quais a sociedade civil foi um elemento muito importante, embora não determinante (Bernhard e Kaya, 2012). Os exemplos de uma sociedade civil ativa na oposição ao regime comunista proliferaram um pouco por todos os países desta região: desde o mais célebre, o sindicato Solidariedade, na Polónia, aos protestos ambientais do Círculo de Danúbio, na Hungria, e à Carta de 77 e várias manifestações, na Checoslováquia (Kopecký, 2005: 1-2; Meyer et al., 2017). Volvidos quase 30 anos desde o início das transições para a democracia, a sociedade civil no Leste europeu permanece como tema de destaque no debate académico. Porém, aquela que outrora era vista como

\footnotetext{
* A autora agradece os comentários e sugestões dos dois avaliadores anónimos.
} 
um exemplo de sociedade vibrante e ativa, tem sido desde a década de 90 do século Xx estudada e descrita pela maioria dos autores como sendo desarticulada e fraca (Bernhard, 1996; Lomax, 1997; Howard, 2002, 2003; Voicu e Voicu, 2009; Lane, 2010). ${ }^{1}$

$\mathrm{Na}$ Europa Central e de Leste, a par da existência de uma sociedade civil apática e desarticulada, os Estados têm, recentemente, vivenciado uma deriva autoritária e antidemocrática. Desde 1989 que os nacionalismos, alicerçados no período pós-Primeira Guerra Mundial e outrora reprimidos pelas políticas de homogeneização das forças soviéticas, têm vindo a ser cultivados e fomentados por partidos de direita conservadora nacionalista. No contexto da crise das dívidas soberanas e da crise migratória, esta deriva autoritária tem-se materializado num retrocesso democrático e na desconstrução do Estado de Direito, assim como na defesa de valores xenófobos e etnocêntricos (Minkenberg, 2013: 9-33; Pirro, 2014a: 613-614; Minkenberg, 2015: 37-42).

Este artigo centra-se nos quatro países que compõem o Grupo de Visegrado - Eslováquia, Hungria, Polónia e República Checa. De entre os países da Europa Central e de Leste, estes Estados foram apresentados pela literatura como os mais promissores relativamente à consolidação e manutenção da democracia (Lewis et al., 1994). No entanto, estes países parecem ter, recentemente, enveredado por uma escalada autoritária (Muller, 2011; Bozóki, 2015). Partindo deste paradoxo, esta investigação pretende refletir sobre a relação entre sociedade civil, associativismo e democracia, tentando perceber qual o contributo da existência (ou ausência) de uma sociedade civil forte na qualidade da democracia neste conjunto de países. Para tal, será mapeada a evolução da sociedade civil nestes Estados durante o período democrático, averiguando se existem diferenças entre os mesmos ao nível do associativismo, sendo ainda mobilizados os principais debates teóricos em torno do tema para estudar esta relação.

O amplo debate em torno do conceito de sociedade civil não trouxe consigo o consenso acerca da definição concreta do termo, tendo, inclusive, aumentado a proliferação de possíveis entendimentos do mesmo (Bernhard, 1993: 307; Cohen e Arato, 1994: 15-18; Tismaneanu, 2001: 977-980). Deste modo, e dada a "aventura semântica" porque tem passado este conceito, afigura-se necessário que se identifique qual a definição teórica utilizada na presente investigação (Tismaneanu, 2001: 977-980). Neste sentido, e dado que não será abordado o papel da sociedade civil na transição para

\footnotetext{
${ }^{1}$ Esta tese é apenas contestada por uma pequena franja de autores, que caracteriza a sociedade civil na Europa Central e de Leste como sendo modestamente estruturada e organizada (Ekiert e Foa, 2017).
} 
a democracia, este conceito não será entendido num sentido gramsciniano, ou seja, como um núcleo independente de atividade política, uma esfera antagónica face ao Estado, de luta contra a tirania (Carothers, 1999: 18-19). Será, antes, visto como uma esfera de auto-organização da sociedade que está entre o Estado e o mercado (Frentzel-Zagorska, 1990: 759). Por outras palavras, sociedade civil é entendida como:

[...] uma esfera de interação social entre a economia e o Estado, composta sobretudo pela esfera íntima (especialmente a família), a esfera das associações (especialmente as associações voluntárias), movimentos sociais e formas de comunicação pública. (Cohen e Arato, 1994: xi; tradução da autora)

[...] o espaço da associação humana sem coação e também o conjunto de redes relacionais - formadas devido à família, fé, interesse e ideologia - que enchem esse espaço. (Walzer, 1995: 7; tradução da autora)

O presente artigo está dividido em quatro partes. Em primeiro lugar, é apresentado o estado da arte sobre a relação entre sociedade civil, associativismo e democracia, bem como sobre a sociedade civil na Europa Central e de Leste, sendo detalhadas as principais tendências e teses acerca do tema. Num segundo momento, são enunciados os métodos e dados utilizados para analisar o fenómeno em estudo e apresentada a seleção de casos. Em terceiro lugar, são expostas e analisadas descritivamente as principais tendências e padrões da evolução da pertença dos indivíduos a organizações voluntárias no Grupo de Visegrado. Finalmente, discutem-se os resultados obtidos à luz das correntes teóricas e explicativas sobre a relação entre sociedade civil, associativismo e democracia enunciadas na revisão da literatura.

\section{A relação entre sociedade civil, associativismo e democracia}

O debate em torno do conceito de sociedade civil tem gerado um outro debate, o da relação entre sociedade civil, associativismo e democracia, que se tem centrado em dois grandes polos: os "otimistas" e os "céticos" (Valkov, 2009: 3-6). No que respeita aos primeiros, desde os escritos de Alexis de Tocqueville na primeira metade do século XIX, muitos cientistas sociais, como Robert Putnam (1993, 2000), Larry Diamond (1999) ou Francis Fukuyama (2001) têm assumido a riqueza da vida associativa de um país, quer como causa, quer como consequência, do seu sucesso e desenvolvimento democráticos.

Segundo Robert Putnam (2000), em Bowling Alone: The Collapse and Revival of American Community, as associações voluntárias incutem nos 
cidadãos hábitos de cooperação e competências necessárias e úteis para a participação na vida pública. Na visão de Theda Skocpol (1999), em "How Americans Became Civic", as organizações voluntárias são uma forma importante de os cidadãos influenciarem o processo de decisão política. A ideia subjacente a estes argumentos é a de que a democracia é fortalecida, e não enfraquecida, quando acompanhada de uma sociedade civil forte e que uma transição para a democracia - bem-sucedida - só é possível na presença de uma sociedade civil robusta (Diamond, 1999: 260). Assim, numa visão neotocquevilliana, uma sociedade ativa e diversa ajuda a potenciar o avanço da democracia, dado que pode "controlar" o Estado, assegurar a garantia dos direitos e liberdades dos cidadãos e promover uma maior participação cívica e política (Carothers, 1999: 21).

Contrapondo e criticando esta ideia neotocquevilliana da relação entre sociedade civil, associativismo e democracia, surgem autores "céticos", como Sheri Berman (1997) ou Nancy Bermeo e Phillip Nord (2000). Estes sugerem que a democracia pode ser enfraquecida pela sociedade civil e que, mais importante do que atender à sociedade civil per se e ao número absoluto de organizações voluntárias, é preciso que se atenda às suas características, à sua natureza e ao seu peso/influência (Valkov, 2009: 3-6). Isto é, de acordo com estes autores, a visão normativa dos neotocquevillianos acerca da sociedade civil tem que ser alterada por uma visão mais neutral e que atenda ao contexto político (Berman, 1997: 427). Seguindo esta linha de pensamento, e argumentando através do exemplo da queda da República de Weimar de que as organizações da sociedade civil podem ser antidemocráticas, Sheri Berman (1997) indica os perigos que uma sociedade civil ativa e forte pode ter no enfraquecimento da democracia e na ascensão de forças antidemocráticas.

\section{A sociedade civil na Europa Central e de Leste}

Com as transições para a democracia e a subsequente realização das primeiras eleições livres e justas, a sociedade civil - que em tempos foi vista como ativa e participativa - enveredou por caminhos de apatia e começou a desagregar-se. Tal facto justifica que, nas últimas duas décadas, vários estudiosos tenham apelidado a sociedade civil nos países pós-comunistas como estruturalmente deficiente. Os inúmeros estudos sobre "capital social" nesta zona do globo têm evidenciado baixos níveis de confiança social, fraco envolvimento na comunidade e em organizações voluntárias, pouca confiança nas instituições políticas e sociais e fraca adesão a formas de participação não-convencionais (Lomax, 1997; Rose et al., 1998; Howard, 2002, 2003; Voicu e Voicu, 2009). 
Dos estudos referidos decorre a justificação da imagem, amplamente espelhada na literatura, de que os países do mundo pós-comunista são "democracias sem cidadãos" (Ekiert e Foa, 2017). Porém, quando comparados os países do mundo comunista entre si, conclui-se que estes não apresentam a mesma tendência/padrão. Isto é, existe uma diferença entre os países que pertenciam à antiga União das Repúblicas Socialistas Soviéticas (URSS) e os países que lhe eram satélites, no que diz respeito à participação em organizações voluntárias da sociedade civil. Embora essa diferença não seja abismal, é notável a maior presença de indivíduos daqueles que eram Estados satélites em organizações voluntárias da sociedade civil, bem como uma maior confiança dos mesmos em instituições políticas e sociais e ainda uma maior tendência para serem rejeitadas opções governativas autoritárias (Howard, 2002: 286-290; Voicu e Voicu, 2009). Relativamente à comparação dos países pós-comunistas com os de outras regiões do globo - como as velhas democracias e os países pós-autoritários (países da América Latina e da Europa do Sul) -, os países pós-comunistas têm os níveis mais baixos de associativismo (Howard, 2002: 290-293; Lane, 2010).

De acordo com a literatura, uma das possíveis justificações para a fraqueza e desarticulação da sociedade civil na Europa Central e de Leste recua a tempos históricos antecedentes do período comunista. As fracas tradições cívicas na Europa Central e de Leste já existiam antes de 1945, embora o regime comunista as tenha agudizado (Putnam, 1993). Durante o período entre guerras, as sociedades caracterizavam-se por ser, maioritariamente, patriarcais, não estando os cidadãos envolvidos em organizações voluntárias (Voicu e Voicu, 2009; Silló, 2016).

Desde a década de 1990, várias investigações têm tentado encontrar possíveis justificações para esta fraqueza e desarticulação da sociedade civil na Europa pós-comunista. De entre estas, parece haver consenso quanto ao legado direto do passado comunista como inibidor do desenvolvimento de uma sociedade civil aberta e ativa. A ideia subjacente a este argumento é a de que, dado que durante o período comunista a maior parte das pessoas era obrigada a integrar organizações (Voicu e Voicu, 2009: 553), hoje em dia, quando confrontadas com a possibilidade de incluir qualquer tipo de associação, não o fazem por manterem presente a memória daquilo que era o associativismo (não voluntário) durante o período comunista (Dahrendorf, 1990; Bernhard, 1996; Howard, 2003).

Um outro argumento, também ele muito ligado ao legado comunista, refere que os cidadãos estavam acostumados a procurar soluções para os seus problemas através de redes interpessoais e não por intermédio da sua participação cívica em organizações voluntárias (Voicu e Voicu, 2009). 
Devido à obrigatoriedade e pouca transparência das organizações durante o período comunista, era através das redes familiares e de amigos que os cidadãos podiam expressar as suas verdadeiras convicções. Atualmente, as redes familiares e de amigos continuam a existir, o que pode ser entendido como um inibidor da participação em organizações voluntárias da sociedade civil (Howard, 2003; Voicu e Voicu, 2009).

Assumindo o impacto do legado comunista, algumas teorias enfatizam o peso das transições democráticas de 1989 como variável preditora do fraco associativismo no período democrático. Este argumento explicativo pode ser fragmentado em dois. Por um lado, foi a forma como as transições ocorreram em muitos países do Leste europeu, isto é, através de negociações pactuadas, que potenciou o "enfraquecimento" da sociedade civil. Houve, nas palavras de Bernhard (1996), uma "desmobilização da sociedade civil insurgente" (demobilization of insurgent civil society), dado que a transição foi acordada entre os líderes dos movimentos e as forças do regime, não tendo o papel da sociedade civil sido determinante durante as negociações. Por outro lado, aquando da transição, a maior parte dos movimentos de contestação ao regime comunista perdeu os seus líderes, que assumiram a representação do Estado democrático. Tomem-se, como exemplos, a eleição de Vaclav Havel para Presidente da Checoslováquia, em 1989, ou a eleição de Lech Walesa como Presidente da Polónia, em 1990 (Kopecký, 2005; Soulet, 2006). Isto é aquilo que Bernhard (1996) designa de "decapitação através do sucesso" (decapitation through success): os movimentos acabam por findar, ou perder a sua força, porque "perdem" os seus líderes (Bernhard, 1996; Lomax, 1997; Howard, 2003).

Um último argumento dá relevância ao generalizado descontentamento que se seguiu ao início das transformações económicas e políticas. Durante o período inicial de transição, havia um certo entusiasmo e uma esperança acerca do que iria advir das transformações económicas e políticas. Porém, pairou sobre as populações um sentimento de traição quando as suas ânsias de uma vida melhor não foram satisfeitas, devido às consequências da transição de uma economia planificada para uma economia de mercado (Howard, 2002, 2003).

\section{Metodologia e dados}

Seguindo o método comparativo dos casos mais similares (Przeworski e Teune, 1970; Lijphart, 1971; Collier, 1993), no presente estudo são analisados os países que compõe o Grupo de Visegrado. O propósito subjacente à escolha destes casos deve-se ao facto de estes Estados terem entre si fortes semelhanças sociais, culturais, históricas, geográficas e económicas. Desde modo, estando estes fatores controlados, garante-se a comparabilidade 
entre os quatro países do Grupo, sendo possível evidenciar as suas semelhanças e, principalmente, as suas diferenças face à temática em análise.

Adicionalmente, a escolha destes casos e a sua comparação prende-se com uma lacuna detetada na literatura sobre o tema. Alguns estudos focam as diferenças - maioritariamente a nível do associativismo - entre os países do mundo pós-comunista e outras regiões do globo, tais como as velhas democracias do mundo ocidental, os países da América Latina e os países da Europa do Sul (Howard, 2003; Lane, 2010). Outros estudos mostram a variação dos níveis de associativismo entre os próprios países do mundo pós-comunista, opondo os antigos Estados satélites às Repúblicas integrantes da URSS (Howard, 2002, 2003; Voicu e Voicu, 2009). Todavia, na literatura sobre estas temáticas não são comparados os antigos Estados satélites entre si, nem os países que outrora formaram a URSS entre si. O presente estudo apresenta-se como um contributo para colmatar a primeira lacuna enunciada.

No que diz respeito à operacionalização do conceito de sociedade civil, este será analisado, exclusivamente, de acordo com a pertença dos indivíduos a organizações voluntárias. Assim, são excluídos outros elementos que compõem este conceito e através dos quais os cidadãos se podem juntar para defender os seus interesses, como por exemplo os movimentos sociais (Ekiert e Foa, 2017). Pesem embora as críticas que têm sido feitas a este tipo de abordagem, a exclusão de outras formas de manifestação da sociedade civil deve-se, unicamente, à ausência de dados para que tal seja feito (ibidem).

Usando três bases de dados - World Values Survey Wave 3 1995-1998 (WVS3 1995-1998), European Values Study 2008 (EVS 2008) e European Values Study 2017 (EVS 2017) - será realizada uma análise descritiva das tendências e padrões dos países do Grupo de Visegrado no que respeita ao associativismo voluntário. Para os anos de 1995-1998, 2008 e 2017, será analisada a pertença dos indivíduos nas seguintes organizações voluntárias: 1) Igreja ou organizações religiosas; 2) organizações desportivas ou recreativas; 3) organizações culturais; 4) sindicatos; 5) partidos políticos e 6) organizações ambientais, ecológicas e de defesa dos animais. No intervalo de tempo 1995-1998, os dados referentes à República Checa são do ano de 1995, os da Polónia de 1997 e os da Hungria e Eslováquia de 1998.

Relativamente aos dados disponíveis e mobilizados neste estudo, devem ser referidas duas limitações. Em primeiro lugar, não se encontram disponíveis dados para os quatro países e para os três períodos de tempo referidos. Assim, para o caso da Polónia, no ano de 1997, só existem dados para a pertença a sindicatos e a partidos políticos. Para o caso da Hungria, no ano de 2017, não existem dados para a pertença a qualquer uma das organizações voluntárias em análise. Em segundo lugar, e uma vez que se 
recorre a bases de dados diferentes, em que as modalidades de resposta são distintas, são analisadas unicamente as percentagens de não integrantes nas organizações voluntárias referidas. Isto porque, se em duas das bases de dados é apresentada uma modalidade de resposta dicotómica - pertença ou não a organizações voluntárias (EVS 2008 e EVS 2017) -, noutra é dividida a pertença a estas mesmas organizações entre a possibilidade de se ser um membro ativo ou um membro não ativo (WVS3 1995-1998).

\section{A sociedade civil no Grupo de Visegrado: evolução, padrões e tendências} Como vem sendo apontado pela literatura, a sociedade civil no Leste europeu caracteriza-se por ser fraca e desarticulada. Através da percentagem total dos quatro casos em estudo, podem ser feitas algumas inferências sobre a evolução longitudinal dos níveis de associativismo voluntário nos países do Grupo de Visegrado. De um modo geral, assistiu-se a um aumento da percentagem de indivíduos que afirma não pertencer a organizações voluntárias entre 1995-1998 e 2008 (ver Gráficos 1-6). Porém, no caso da República Checa, duas exceções merecem ser indicadas: houve um aumento percentual dos indivíduos que integram organizações culturais (ver Gráfico 3) bem como os que integram organizações ambientais, ecológicas e de defesa dos animais (ver Gráfico 6). Já entre 2008 e 2017, a percentagem de indivíduos que afirma não pertencer a organizações voluntárias decresceu ligeiramente se considerarmos o total do Grupo. No entanto, no caso da Eslováquia, esta percentagem manteve-se inalterada e/ou aumentou pontualmente em todas as organizações voluntárias em estudo (ver Gráficos 1 a 6).

No que diz respeito à análise da percentagem total dos quatro casos em cada organização voluntária em específico, é nas organizações de cariz religioso que se encontra uma maior variação: se em 1995-1998 78,1\% dos inquiridos dizia não pertencer a nenhuma destas organizações, este valor era de 93,7\% e de 90,5\% em 2008 e 2017 respetivamente (ver Gráfico 1). Seguem-se as organizações desportivas ou recreativas, com 79,5\% em 1995-1998, 91,3\% em 2008 e $84,1 \%$ em 2017, bem como os sindicatos, com 85,4\% em 1995-1998, 95,2\% em 2008 e 94,20\% em 2017 (ver Gráficos 2 e 4, respetivamente).

As restantes organizações voluntárias têm variações mais baixas. A principal razão para tal prende-se com o facto de as percentagens de não pertença já serem muito elevadas em 1995-1998. Nas organizações culturais, o número de não pertencentes aumentou de 93,2\% para 95,3\% em 2008 e decresceu para 91\% em 2007; nos partidos políticos, este número aumentou de $95,4 \%$ para $98,4 \%$ em 2008 , decrescendo para $97,6 \%$ em 2017; e nas organizações ambientais, ecológicas e de defesa dos animais, a percentagem de inquiridos que não é membro aumentou de 95,5\% para 97,3\% em 2008 e 
decresceu para 94,5\% em 2017 (ver Gráficos 3, 5 e 6, respetivamente). Desta análise, é possível inferir que se em 1995-1998 a variação entre as organizações era considerável $(78,1 \%$ de não pertencentes a organizações religiosas contra 95,5\% de não pertencentes a organizações ambientais, ecológicas e de defesa dos animais), em 2008 todos os tipos de organizações analisadas têm uma percentagem de não pertença superior a 90\%. Esta última tendência repete-se em 2017, com a exceção das organizações desportivas e recreativas onde a percentagem de não pertença total é de $84,1 \%$.

Quanto às diferenças entre os países do Grupo de Visegrado, estas afiguram-se relevantes quando analisadas tendo em conta os vários tipos de organizações voluntárias. Relativamente às organizações religiosas, entre o período de 1995-1998 e 2008, a Eslováquia foi o país que apresentou maior variação, tendo estas associações perdido $20 \%$ dos seus membros (ver Gráfico 1). Entre 2008 e 2017, a pertença a organizações religiosas decresceu cerca de 5\% na República Checa e na Polónia e manteve-se na Eslováquia. Em 2017, os países em análise apresentam níveis de não pertença entre os $88,1 \%$ (República Checa) e $91,9 \%$ (Eslováquia). Ainda no que toca a organizações religiosas, é interessante atender aos valores do caso polaco: este, que é um país fortemente religioso, apresenta níveis de não pertença a este tipo de organizações de 96,4\% em 2008 e 91,8\% em 2017.

\section{GRÁFICO 1 - Percentagem de inquiridos que não pertence a organizações voluntárias, 1995-1998, 2008 e 2017: igreja e organizações religiosas}

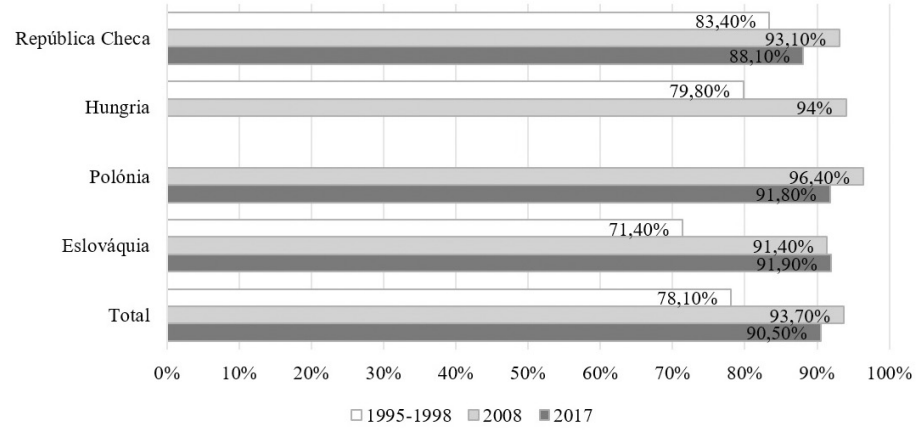

Fonte: elaboração da autora a partir de WVS3 1995-1998 (2014), EVS 2008 (2011) e EVS 2017 (2018).

Em relação a organizações desportivas ou recreativas, é a República Checa que apresenta os maiores níveis de pertença a estas organizações nos três períodos em análise (ver Gráfico 2). Em 1995-1998, a percentagem de não pertença era de $76,4 \%$, tendo aumentado para $80,2 \%$ em 2008 e diminuído 
para $64,7 \%$ em 2017. Nos restantes países, os valores de não pertença rondavam os $95 \%$ em 2008 e 2017 . No que diz respeito às organizações culturais, a variação percentual ao longo dos anos em análise é muito baixa (ver Gráfico 3). A percentagem de não pertença a este tipo de organizações tem-se fixado entre os $94 \%$ e os $99 \%$ na Hungria, Polónia e Eslováquia. Contudo, na República Checa este valor percentual tem vindo a decrescer de $91,1 \%$ em 1995-1998 para 89,5\% em 2008 e para 81,2\% em 2017.

\section{GRÁFICO 2 - Percentagem de inquiridos que não pertence a organizações voluntárias,}

1995-1998, 2008 e 2017: organizações desportivas e recreativas

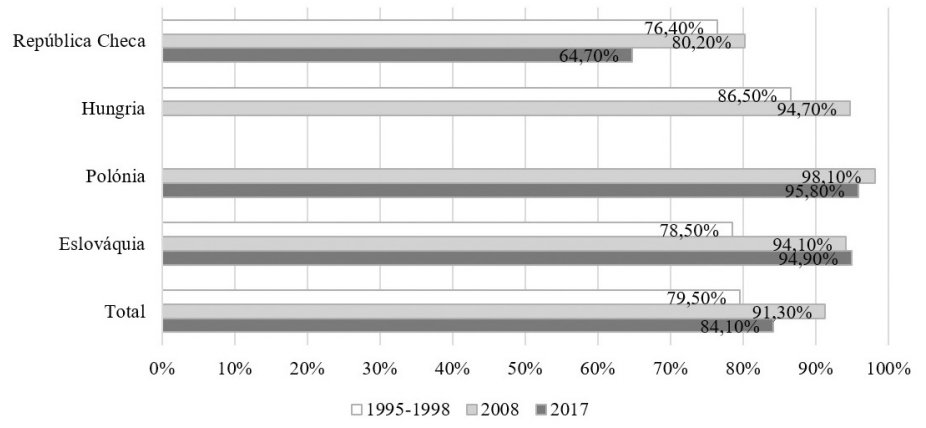

Fonte: elaboração da autora a partir de WVS3 1995-1998 (2014), EVS 2008 (2011) e EVS 2017 (2018).

\section{GRÁFICO 3 - Percentagem de inquiridos que não pertence a organizações voluntárias,} 1995-1998, 2008 e 2017: organizações culturais

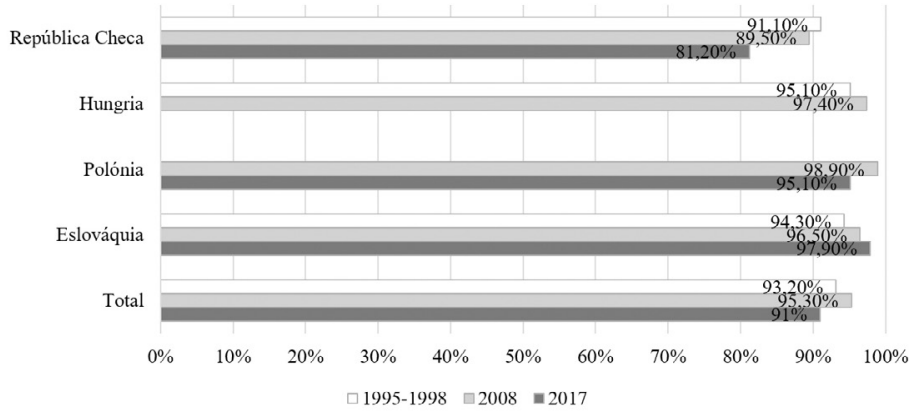

Fonte: elaboração da autora a partir de WVS3 1995-1998 (2014), EVS 2008 (2011) e EVS 2017 (2018).

Quanto a sindicatos, em 1995-1998, a Hungria e a Polónia registavam uma percentagem de não pertença a estas organizações de $87,8 \%$ e $90 \%$, respetivamente (ver Gráfico 4). Na República Checa e na Eslováquia estes valores 
rondavam os $81-82 \%$. Estas percentagens aumentaram e, em 2008 e 2017, os quatro países tinham níveis de não pertença a sindicatos de cerca de $92-95 \%$. Em relação aos partidos políticos, estes registam níveis percentuais de não pertença muito baixos em todos os países, quer em 1995-1998, com cerca de $95 \%$, quer em 2008 e em 2017, com cerca de 98\% (ver Gráfico 5). À semelhança dos partidos políticos, também as organizações ambientais, ecológicas e de defesa dos animais registam níveis percentuais de não pertença muito baixos, quer em 1995-1998, com cerca de 95\%, quer em 2008 e em 2017, com cerca de $97 \%$ (ver Gráfico 6). A exceção a este padrão é o caso checo que regista uma não pertença a este tipo de organizações de 87,5\%, em 2017.

\section{GRÁFICO 4 - Percentagem de inquiridos que não pertence a organizações voluntárias, 1995-1998, 2008 e 2017: sindicatos}

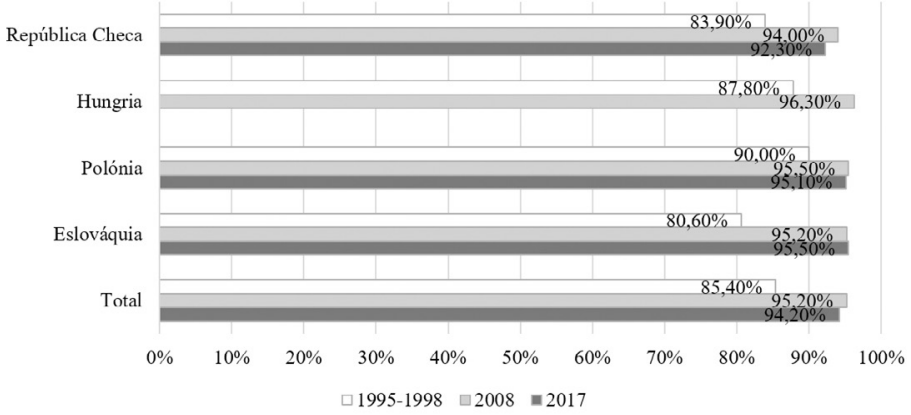

Fonte: elaboração da autora a partir de WVS3 1995-1998 (2014), EVS 2008 (2011) e EVS 2017 (2018).

GRÁFICO 5 - Percentagem de inquiridos que não pertence a organizações voluntárias, 1995-1998, 2008 e 2017: partidos políticos

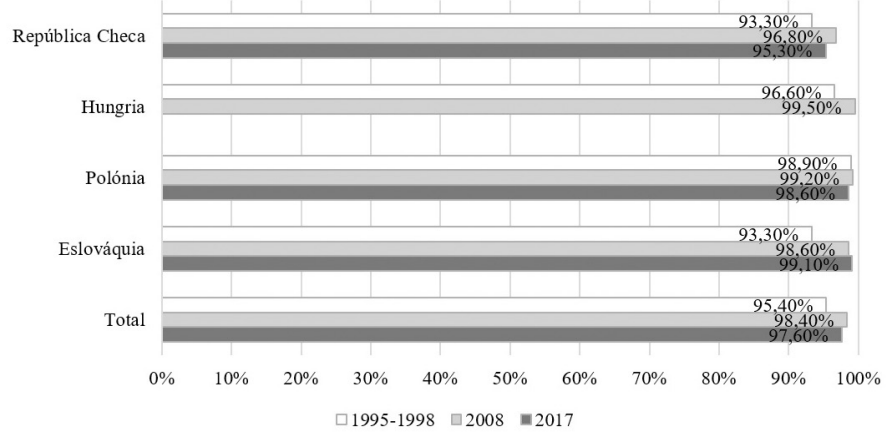


GRÁFICO 6 - Percentagem de inquiridos que não pertence a organizações voluntárias, 1995-1998, 2008 e 2017: organizações ambientais, ecológicas e de defesa dos animais

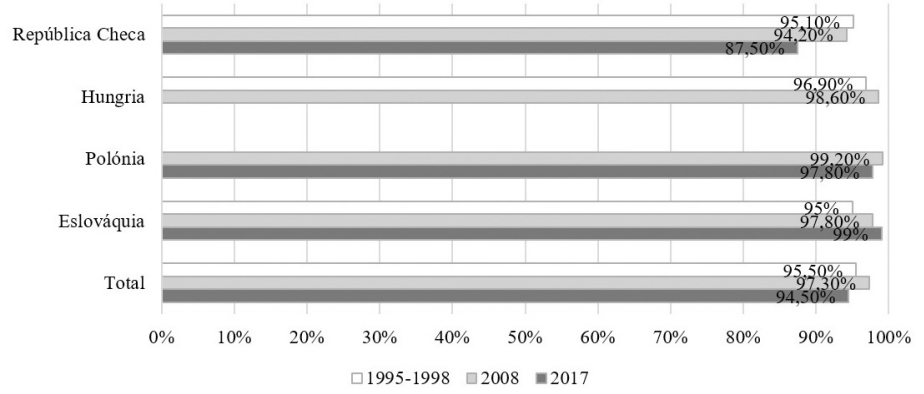

Fonte: elaboração da autora a partir de WVS3 1995-1998 (2014), EVS 2008 (2011) e EVS 2017 (2018).

Tomando como referente as percentagens totais do envolvimento dos cidadãos dos quatro países nos vários tipos de organizações, existem algumas ilações que podem ser retiradas. Em primeiro lugar, e embora o associativismo voluntário seja fraco no Grupo de Visegrado, a República Checa é o país em que os indivíduos mais integram organizações. Com a exceção das organizações de cariz religioso, em 1995-1998, este país tem valores percentuais de não pertença a organizações voluntárias sempre inferiores aos valores referentes ao total dos quatro países. Em segundo lugar - embora tendo em conta a limitação que este caso apresenta nesta análise - a Polónia apresenta valores percentuais de não pertença a organizações voluntárias sempre superiores aos valores referentes ao total dos quatro países. Em terceiro lugar, a Hungria, à semelhança da Polónia, também apresenta valores percentuais de não pertença a organizações voluntárias sempre superiores aos valores totais, em 1995-1998 e em 2008. Todavia, os valores polacos tendem a ser superiores aos húngaros, salvo exceções pontuais. Em quarto lugar, a Eslováquia apresenta valores percentuais de não pertença a organizações voluntárias superiores aos valores totais apenas em 2017.

\section{A relação entre sociedade civil, associativismo e democracia no Grupo de Visegrado: uma reflexão crítica}

Os dados apresentados ajudam a corroborar a ideia patente na literatura de que a sociedade civil no Leste europeu está em "declínio" (Bernhard, 1996; Lomax, 1997; Howard, 2002, 2003; Voicu e Voicu, 2009; Lane, 2010). Embora se verifiquem algumas diferenças entre os quatro casos apresentados - a República Checa apresenta melhores níveis de associativismo 
no Grupo de Visegrado, por oposição à Polónia que apresenta os valores mais baixos de associativismo -, estas não são excessivamente acentuadas e corroboram os padrões dos níveis de associativismo que a literatura tem vindo a evidenciar sobre as sociedades pós-comunistas.

As evidências empíricas acerca dos fracos níveis de participação em organizações da sociedade civil nos países da Europa Central e de Leste ajudam a enquadrar e a ilustrar a relação teórica entre sociedade civil, associativismo e democracia nesta região. Conforme anteriormente apresentadas, existem duas correntes de pensamento que, ao longo dos anos, têm teorizado sobre esta relação - os "otimistas" (Putnam, 1993, 2000; Diamond, 1999; Fukuyama, 2001) e os "céticos" (Berman, 1997; Bermeo e Nord, 2000). Seguindo a lógica dos primeiros, a democracia nos países do Grupo de Visegrado está em risco de ser apoderada pelas forças antidemocráticas. De acordo com a segunda corrente, os países em estudo, pelos níveis de associativismo que têm, podem não enfrentar qualquer tipo de crise democrática, pois um forte associativismo pode levar à queda de um regime democrático.

As democracias dos países de Visegrado foram, de entre os países da Europa Central e de Leste que iniciaram a transição para a democracia em 1989, aquelas sobre as quais recaiu a maior esperança num futuro democrático, uma vez que foram estes os países que melhor ultrapassaram as vicissitudes aliadas ao processo de transição democrática (Lewis et al., 1994). Todavia, tal não indica que o colapso democrático nestes países seja impossível. A título de exemplo, veja-se o caso da Hungria, onde o partido nacionalista radical de extrema-direita, Jobbik, tem visto a sua força aumentar de tal forma que obteve $19,06 \%$ dos votos nas eleições de 2018 . Ou o exemplo dos partidos eslovacos, SNS e L'SNS, também de extrema-direita, que nas eleições de 2016 obtiveram 8,6\% e 8\% dos votos, respetivamente.

A relutância generalizada dos cidadãos do Grupo de Visegrado em participar em organizações voluntárias da sociedade civil significa, por um lado, que estes não integram organizações democráticas, mas por outro que também não pertencem a associações voluntárias antidemocráticas. Neste sentido, a eleição de forças como o Jobbik, o SNS ou o L'SNS não pode ser consequência direta da grande capacidade de mobilização popular das organizações voluntárias antidemocráticas, nem da fraca capacidade mobilizadora das organizações democráticas. Para explicar o sucesso eleitoral destas três forças políticas, têm que ser tidas em conta outras variáveis explicativas - que não a fraca e desarticulada sociedade civil -, como a personalidade dos seus líderes, o contexto político, económico e social, entre outras (Pirro, 2014a, 2014b). 
Se a fraca sociedade civil não explica o surgimento de forças antidemocráticas no Leste europeu, também não seria razoável afirmar que baixos níveis de associativismo voluntário desde a queda do muro de Berlim têm ajudado na promoção do desenvolvimento democrático dos países de Visegrado. Ao invés, e seguindo os argumentos de Robert Putnam (2000) e Theda Skocpol (1999), o fraco associativismo na Europa Central e de Leste pode hipotecar a qualidade da democracia. Isto porque, por um lado, as associações voluntárias incutem nos cidadãos valores e hábitos de cooperação, assim como competências transversais para que se participe na esfera pública. Por outro lado, as organizações voluntárias são um canal determinante para que os cidadãos influenciem o processo de decisão política. Assim, e dada a inexistência de uma cultura associativa forte, as populações dos países do Grupo de Visegrado não só não têm a oportunidade de desenvolver as suas capacidades democráticas (através do associativismo), como não veem as suas vozes e opiniões representadas no processo de decisão política.

\section{Conclusão}

Desde o final dos anos 70 do século xx e, principalmente, desde a queda do Muro de Berlim e da subsequente transição para a democracia das antigas Repúblicas Populares da Europa Central e de Leste, houve um ressurgimento do debate em torno do conceito de sociedade civil. Na literatura, aquela que durante o período comunista era vista como um exemplo de sociedade civil vibrante e ativa, tem recentemente sido estudada e descrita pela maioria dos autores como sendo desarticulada e fraca. Num contexto de ascensão das forças antidemocráticas, este artigo visou refletir sobre a relação entre sociedade civil, associativismo e democracia. Estudando os países do Grupo de Visegrado, este artigo tinha como objetivo perceber qual o contributo da existência (ou ausência) de uma sociedade civil forte na qualidade da democracia nestes países.

O "fenómeno" da não participação em organizações voluntárias da sociedade civil no Leste europeu não é algo novo, acidental ou temporário. Isto porque, e como foi argumentado e defendido, desde as transições para a democracia que os níveis percentuais de não pertença a este tipo de associações têm aumentado. Neste estudo foi apresentada, através da uma análise descritiva, a fraca adesão dos cidadãos do Grupo de Visegrado a organizações voluntárias da sociedade civil, sendo a República Checa o país com melhores níveis de participação e a Polónia o que apresenta os piores resultados.

No que diz respeito à relação entre sociedade civil, associativismo e democracia, a relutância generalizada dos cidadãos do Grupo de Visegrado 
em participar em organizações voluntárias da sociedade civil significa não só que estes não integram organizações democráticas, como também que não pertencem a associações voluntárias antidemocráticas. Como foi demonstrado, esta tendência não coloca em risco a sobrevivência da democracia nestes países - sendo rejeitada a visão dos "otimistas" - porém, os fracos níveis percentuais de participação em organizações voluntárias também podem não promover estabilidade e desenvolvimento democráticos nesta região do globo - sendo refutada a visão dos "céticos". Assim, o retrocesso democrático que estes países têm enfrentado, com a presença de partidos de extrema-direita nos seus parlamentos nacionais, não deve ser atribuído aos fracos níveis de associativismo. Para explicar este fenómeno devem ser mobilizadas outras variáveis, como a personalidade dos líderes destes partidos ou o contexto político, económico e social destes países.

O presente artigo centrou-se na análise da Eslováquia, Hungria, Polónia e República Checa, países pouco estudados pela academia portuguesa, sendo este um dos seus principais contributos. Adicionalmente, a presente investigação pretendeu ser um complemento à discussão empírica e aos estudos já feitos sobre a fraca e desarticulada sociedade civil nesta zona do globo, bem como um contributo aos estudos sobre a relação entre sociedade civil, associativismo e democracia. Todavia, existem caminhos que ainda podem ser trilhados no que respeita a esta temática. Uma vez que esta investigação reduziu o estudo da sociedade civil ao associativismo, afigura-se interessante perceber os padrões e tendências de outras formas de mobilização social através das quais os cidadãos se podem juntar para defender os seus interesses, como os movimentos sociais.

\section{Referências bibliográficas}

Berman, Sheri (1997), "Civil Society and the Collapse of the Weimar Republic", World Politics, 49(3), 401-429.

Bermeo, Nancy; Nord, Philip (orgs.) (2000), Civil Society before Democracy: Lessons from Nineteenth-Century Europe. London: Rowman and Littlefield.

Bernhard, Michael (1993), "Civil Society and Democratic Transition in East Central Europe”, Political Science Quarterly, 108(2), 307-326.

Bernhard, Michael (1996), "Civil Society after the First Transition: Dilemmas of Post-Communist Democratization in Poland and Beyond", Communist and Post-Communist Studies, 29(3), 309-330.

Bernhard, Michael; Kaya, Ruchan (2012), "Civil Society and Regime Type in European Post-Communist Countries - The Perspective Two Decades after 1989-1991”, Taiwan Journal of Democracy, 8(2), 113-126. 
Bozóki, András (2015), “Broken Democracy, Predatory State, and Nationalist Populism”, in Péter Kraszter; Jon Van Til (orgs.), The Hungarian Patient. Social Opposition to an Illiberal Democracy. Budapest: Central European University Press, 3-36.

Carothers, Thomas (1999), "Think Again: Civil Society”, Foreign Policy, 117, 18-29.

Cohen, Jean L.; Arato, Andrew (1994), Civil Society and Political Theory. Massachusetts: The MIT Press.

Collier, David (1993), "The Comparative Method", in Ada W. Finifter (org.), Political Science: The State of the Discipline II. Washington, D.C.: American Political Science Association, 105-119.

Dahrendorf, Ralf (1990), Reflections on the Revolution in Europe. New York: Time Books.

Diamond, Larry (1999), Developing Democracy: Toward Consolidation. Baltimore: Johns Hopkins University Press.

Ekiert, Grzegorz; Foa, Roberto (2017), "The Weakness of Postcommunist Civil Society Reassessed”, European Journal of Political Research, 56(2), 419-439.

EVS 2008 (2011), European Values Study 2008: Integrated Dataset (EVS 2008). GESIS Data Archive, Cologne. ZA4800 Data file Version 3.0.0. DOI: 10.4232/1.11004. Última consulta a 17.07.2017.

EVS 2017 (2018), European Values Study 2017: Integrated Dataset (EVS 2017). GESIS Data Archive, Cologne. ZA7500 Data file Version 1.0.0. DOI: 10.4232/1.13090. Última consulta a 14.02.2019.

Frentzel-Zagorska, Janina (1990), "Civil Society in Poland and Hungary", Soviet Studies, 42(4), 759-777.

Fukuyama, Francis (2001), "Social Capital, Civil Society and Development", Third World Quarterly, 22(1), 7-20.

Howard, Marc Morjé (2002), "Postcommunist Civil Society in Comparative Perspective", Demokratizatsiya, 10(3), 285-305.

Howard, Marc Morjé (2003), The Weakness of Civil Society in Post-Communist Europe. Cambridge: Cambridge University Press.

Kopecký, Petr (2005), "Civil Society, Uncivil Society and Contentious Politics in Post-Communist Europe”, in Petr Kopecký; Cas Mudde (orgs.), Uncivil Society? Contentious Politics in Post-Communist Europe. London: Routledge, 1-17.

Lane, David (2010), "Civil Society in the Old and New Member States", European Societies, 12(3), 293-315.

Lewis, Paul; Lomax, Bill; Wightman, Gordon (1994), "The Emergence of Multi-Party Systems in East-Central Europe. A Comparative Analysis", in Geoffrey Pridham; Tatu Vanhanem (orgs.), Democratization in Eastern Europe: Domestic and International Perspectives. London: Routledge, 151-189.

Lijphart, Arend (1971), "Comparative Politics and Comparative Method", The American Political Science Review, 65(3), 682-693. 
Lomax, Bill (1997), "The Strange Death of 'Civil Society' in Post-Communist Hungary”, Journal of Communist Studies and Transition Politics, 13(1), 41-63.

Meyer, Michael; Moder, Clara Maria; Neumayr, Michaela; Traxler, Nicole; Vandor, Peter (2017), "Patterns in Civil Society in Central and Eastern Europe: A Synthesis of 16 Country Reports and an Expert Survey", in Peter Vandor; Nicole Traxler; Reinhard Millner; Michael Meyer (orgs.), Civil Society in Central and Eastern Europe: Challenges and Opportunities. Vienna: ERSTE Foundation, 12-41.

Minkenberg, Michael (2013), “The European Radical Right and Xenophobia in West and East: Trends, Patterns and Challenges”, in Ralf Melzer; Sebastian Serafin (orgs.), Right-Wing Extremism in Europe - Country Analyses, Counter-Strategies and Labor-Market Oriented Exit Strategies. Berlin: Friedrich-Ebert-Stiftung Forum Berlin, 9-34. Minkenberg, Michael (2015), "Profiles, Patterns, Process. Studying the East European Radical Right in Its Political Environment”, in Michael Minkenberg (org.), Transforming the Transformation? The East European Radical Right in the Political Process. Oxon: Routledge, 27-56.

Muller, Jan-Werner (2011), “The Hungarian Tragedy”, Dissent, 52(2), 5-10.

Pirro, Andrea L. P. (2014a), "Populist Radical Right in Central and Eastern Europe: The Different Context and Issues of the Prophets of the Patria", Government and Opposition, 49(4), 600-629.

Pirro, Andrea L. P. (2014b), "Digging into the Breeding Ground: Insights into the Electoral Performance of Populist Radical Right Parties in Central and Eastern Europe", East European Politics, 30(2), 246-270.

Przeworski, Adam; Teune, Henry (1970), Logic of Comparative Social Inquiry. Minnesota: John Wiley \& Sons.

Putnam, Robert (1993), Making Democracy Work: Civic Tradition in Modern Italy. Princeton: Princeton University Press.

Putnam, Robert (2000), Bowling Alone: The Collapse and Revival of American Community. New York: Simon and Schuster.

Rose, Richard; Mishler, William; Haerpfer, Christian (1998), Democracy and Its Alternatives: Understanding Post-Communist Societies. Baltimore: Johns Hopkins University Press.

Silló, Ágota (2016), "The Development of Volunteering in Post-Communist Societies. A Review”, Acta Universitatis Sapientiae, Social Analysis, 6(1), 93-110.

Skocpol, Theda (1999), "How Americans Became Civic", in Theda Skocpol; Morris P. Fiorina (orgs.), Civic Engagement in American Democracy. Washington: Brookings Institution Press, 27-80.

Soulet, Jean-François (2006), História da Europa de Leste - Da Segunda Guerra Mundial aos nossos dias. Lisboa: Teorema.

Tismaneanu, Vladimir (2001), "Civil Society, Pluralism, and the Future of East and Central Europe”, Social Research, 68(4), 977-991. 
Valkov, Nikolay (2009), "Membership in Voluntary Organizations and Democratic Performance: European Post-Communist Countries in Comparative Perspective”, Communist and Post-Communist Studies, 42(1), 1-21.

Voicu, Mălina; Voicu, Bogdan (2009), "Volunteers and Volunteering in Central and Eastern Europe", Slovak Journal of Sociology, 41(6), 539-563.

Walzer, Michael (1995), “The Concept of Civil Society”, in Michael Walzer (org.), Towards a Global Civil Society. Oxford: Berghahn Books, 7-28.

WVS3 1995-1998 (2014), World Values Survey Wave3, 1995-1998 - World Values Survey

Association (2014): Official Aggregate v.20140921. Madrid: Asep/JDS. Consultado a 17.07.2017, em http://www.worldvaluessurvey.org/WVSDocumentationWV3.jsp.

Artigo recebido a 05.03.2018

Aprovado para publicação a 27.06.2019

\section{Mariana Carmo Duarte}

Centro de Investigação e Estudos de Sociologia, Instituto Universitário de Lisboa

Edifício ISCTE, Av. das Forças Armadas, 1649-026 Lisboa, Portugal

Contacto: Mariana_Silva_Duarte@iscte-iul.pt

ORCID: https://orcid.org/0000-0003-2213-2920

\section{Civil Society and Democracy: The Visegrad Group in a Comparative Perspective}

This article aims to understand the influence of civil society on the quality of democracy in the Visegrad Group countries (Slovakia, Hungary, Poland and the Czech Republic). To do so, the evolution of civil society in these countries was mapped, and the main theoretical debates on the theme were mobilised. Using data from international surveys over three different periods of time, it was found that citizen adherence to voluntary civil society organizations is weak in the four countries. These differences notwithstanding, the Czech Republic presents the best levels of participation in voluntary organizations,

\section{Société civile et démocratie: le Groupe de Visegrád en perspective comparative}

Cet article vise à déduire l'influence de la société civile sur la qualité de la démocratie dans les pays du Groupe de Visegrád (Slovaquie, Hongrie, Pologne et République tchèque). À cette fin, l'évolution de la société civile dans ces États a été cartographiée, de même que les principaux débats théoriques autour du thème. En utilisant les données d'enquêtes internationales menées sur trois périodes distinctes, on peut conclure que l'adhésion des citoyens à des organisations volontaires de la société civile est faible dans les quatre pays. Toutefois, en ce qui concerne les différences, la République tchèque affiche 
while Poland displays the worst. When analysing the relationship between civil society, volunteering associations and democracy, it can be concluded that, even though these countries may be facing a democratic setback, it should not be attributed to the weak levels of citizen participation in volunteering associations. Keywords: associativism; authoritarianism; Central Europe; civil society; democracy; East Europe. les taux de participation les plus élevés au sein des organisations volontaires, à la différence de la Pologne, qui enregistre les pires. En analysant les relations entre société civile, mouvement associatif et démocratie, on peut conclure que, même si ces pays peuvent être confrontés à une dérive autoritaire, elle ne doit pas être imputée à de faibles niveaux du mouvement associatif.

Mots-clés: autoritarisme; démocratie; Europe centrale; Europe orientale; mouvement associatif; société civile. 
